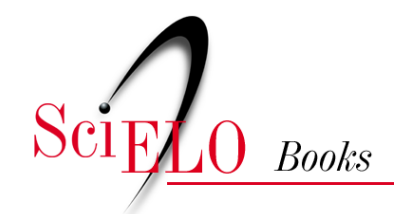

\title{
Prefácio
}

\section{Rebecca Abers}

ABERS, R. Prefácio. In: LAVALLE, A.G., CARLOS, E., DOWBOR, M., and SZWAKO, J., comps.

Movimentos sociais e institucionalização: políticas sociais, raça e gênero no Brasil pós-transição

[online]. Rio de Janeiro: EDUERJ, 2018, pp. 13-18. Sociedade e política collection. ISBN: 978-85-7511479-7. https://doi.org/10.7476/9788575114797.0002.

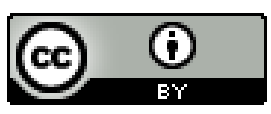

All the contents of this work, except where otherwise noted, is licensed under a Creative Commons Attribution 4.0 International license.

Todo o conteúdo deste trabalho, exceto quando houver ressalva, é publicado sob a licença Creative Commons Atribição 4.0.

Todo el contenido de esta obra, excepto donde se indique lo contrario, está bajo licencia de la licencia Creative Commons Reconocimento 4.0 . 


\section{Prefácio}

Nas décadas de 1990 e 2000, o Brasil apareceu no cenário internacional como foco de experimentação criativa na produção de políticas públicas que envolviam movimentos sociais no interior do processo decisório. Nos anos 1990, eram os orçamentos participativos e outras iniciativas locais, bem como a criação de sistemas de políticas públicas com participação em nível nacional, tais como o Sistema Único de Saúde. Nos anos 2000, especialmente a partir de 2003 com o advento do governo federal do Partido dos Trabalhadores, essa experimentação subiu de escala com o fortalecimento de conselhos e conferências, e uma diversidade de outros tipos de arranjos participativos que envolveram movimentos sociais não somente na formulação das políticas, mas também na sua implementação.

Ao lado dessa experimentação na prática, surgiu uma literatura acadêmica que também experimentou, contribuindo de maneira original para os estudos de movimentos sociais, democracia e sociedade civil. Num primeiro momento, isso envolveu reacender o antigo debate sobre democracia participativa, agora em torno de experiências reais muito mais amplas em termos numéricos do que havia acontecido no passado em outros lugares do mundo (com a exceção, talvez, da experiência do estado indiano de Kerala, que também envolveu milhões de pessoas). Uma literatura inicialmente ufanista e militante foi rapidamente complementada por pesquisas empíricas bem fundamentadas que revelavam as complexidades e limitações das iniciativas participativas. Ao mes- 
mo tempo, estudiosos começaram a ampliar o olhar em várias direções. Enquanto alguns examinaram a inserção das instituições participativas em estruturas políticas e partidárias mais amplas, outros estudaram as diversas maneiras por meio das quais atores sociais interagiam com o Estado para além de instituições formalmente criadas para tanto.

A criatividade na prática política foi acompanhada pela criatividade intelectual. Extrapolando o terreno das instituições participativas, as análises testaram os pressupostos de boa parte da bibliografia sobre movimentos sociais que os concebia como essencialmente externos à estrutura do Estado e que presumia que a proximidade de movimentos às instituições políticas implicaria necessariamente na sua desmobilização. Os estudos brasileiros mostraram o contrário: que movimentos podiam interagir sistematicamente com instituições estatais, em dinâmicas não necessariamente desmobilizadoras. Demonstrou-se também que a aproximação entre movimentos e governos não é novidade no Brasil: atores de movimentos sociais negociavam com e até participavam em governos muito antes da ascendência da esquerda ao poder governamental. Mesmo nos governos petistas, a proximidade entre movimentos e alguns atores estatais não implicou na ausência de conflitos. Muitas vezes, porém, esses se manifestavam não tanto como contendas entre atores no Estado e outros na sociedade, mas entre atores que defendiam projetos distintos, ocupando arenas estatais diferentes, com suas respectivas alianças na sociedade.

A maior parte desse debate escolheu como marco conceitual de diálogo as teorias de movimentos sociais e de sociedade civil, deixando de lado uma melhor compreensão teórica do que acontecia no interior do Estado. A criação de instituições eficazes de acesso de movimentos ao Estado foi frequentemente vista em termos vagos que deixaram mais perguntas do que respostas, como foi o caso do conceito de "vontade política", usado por muitos 
estudiosos para explicar a eficácia maior de algumas instituições participativas.

Este livro surge como importante contribuição para corrigir este viés "centrado na sociedade" ao privilegiar a compreensão da natureza do Estado no que diz respeito a sua relação com os movimentos. Percebendo as limitações da literatura sobre participação e movimentos sociais para esse fim, os autores embarcaram em uma viagem de reconhecimento e captura de conceitos do neoinstitucionalismo histórico, campo pouco conhecido pelos estudiosos de movimentos sociais brasileiros. A leitura que fazem dessa literatura é cuidadosa e seletiva, privilegiando autores mais "sociológicos", como Evans, Skocpol e Mann, que oferecem ricos trabalhos conceituais sobre a natureza e funcionamento das organizações estatais. Também resgatam debates sobre intermediação de interesses no corporativismo e pluralismo.

No encontro dessas literaturas, os autores constroem um marco conceitual próprio para entender como a institucionalização de demandas de movimentos sociais ocorre e para explorar as consequências para a capacidade dos movimentos de influenciar o processo de decisão governamental. Conceitos como "encaixe" e "domínio de agência", que o leitor conhecerá a fundo nas páginas a seguir, nos oferecem uma gramática para tornar visível a variedade de maneiras em que movimentos sociais participam de instituições de políticas públicas. Os capítulos empíricos avançam mais ainda, explorando como esses conceitos podem ser utilizados e oferecendo teses para explicar como os pontos de acesso para movimentos chegam a ser institucionalizados no interior do Estado. Demonstram de maneira detalhada como diferentes histórias de organização e interação entre movimentos e políticas públicas resultam em uma variedade enorme de estruturas de acesso. A permeabilidade do Estado é definitivamente heterogênea.

A obra avança o atual debate brasileiro sobre o papel dos movimentos nas políticas públicas em uma direção especialmente 
importante. Em uma etapa anterior muito frutífera, as pesquisas passaram de um foco centrado na "participação" dos movimentos sociais para o exame da "interação" entre movimentos e Estado. Assim começaram a desconstruir a noção de que o encontro entre atores do Estado e da sociedade consistia em uma espécie de conversa através de grades que separavam dois mundos. Na presente obra, os autores vão além: propõem pensar não somente na interação, mas também na "mútua constituição" de movimentos e Estado.

Trata-se de dois passos simultâneos na crítica ao pressuposto de que os movimentos operariam de maneira independente do Estado. Primeiro: os movimentos são profundamente influenciados pelas políticas públicas e pelas regras institucionais que definem suas formas de participação. Segundo: essas políticas e regras foram criadas em grande parte a partir de processos de construção institucional em que os próprios movimentos participaram. Assim, para além da ideia de interação, a noção de mútua constituição sugere que os atores nos movimentos e nas agências estatais não apenas se interrelacionam a partir de terrenos institucionais fixos, mas participam na construção destes.

Ao tratar de maneira teoricamente substanciada da mútua constituição da sociedade civil e do Estado, os autores buscam dar continuidade a um debate truncado que surgiu em torno da publicação da coletânea Bringing the State Back In, organizada por Peter Evans, Dietrich Rueschemeyer e Theda Skocpol, em 1985. Vários intérpretes acusaram a perspectiva associada a esse livro, que veio a ser chamada de perspectiva "centrada no Estado", de atribuir causalidade excessiva ao Estado nos processos sociais e políticos. Duas obras articularam importantes respostas a essas críticas ao teorizar o Estado e a sociedade como mutuamente constituídos: The Sources of Social Power de Michael Mann (1993) e Embedded Autonomy de Peter Evans (1995). Essa investida conceitual e empírica no estudo dos impactos mútuos de organizações 
da sociedade e do Estado, no entanto, não proliferou, talvez em função do crescimento, nos anos 1990, do debate em torno do neoliberalismo.

Mais recentemente, Evans e Mann participaram do debate em torno do conceito de "capacidade estatal", questionando a associação entre capacidade e impermeabilidade do Estado. Os autores do presente volume encontram nesse debate várias pistas para a proposta da mútua constituição. Um dos conceitos centrais apresentados no livro - os "encaixes" que institucionalizam o acesso de atores sociais ao Estado - é adaptado a partir de uma obra de Skocpol, escrita nos anos 1990 em parte para defender a perspectiva "centrada no Estado", então sob ataque. A autora desafiava a proposta "centrada na sociedade" de autores como Putnam, que atribuía o desempenho estatal unicamente ao que poderíamos chamar de capacidade societária. Skocpol argumentou que as associações são profundamente influenciadas pelas políticas e práticas governamentais. Talvez por isso, ela não traz instrumentos conceituais suficientes para entender como a sociedade participa na constituição dos "encaixes".

O presente livro contribui de maneira significativa para preencher esta lacuna e assim empurrar a abordagem neoinstitucionalista de autores como Skocpol um pouco mais para além da dicotomia entre perspectivas centradas na sociedade e no Estado. Inspirados na discussão sobre a mútua constituição de Estado e da sociedade presente na literatura sobre o corporativismo societal, os autores abordam os mecanismos de construção de domínios de agência, por meio dos quais em décadas recentes uma heterogeneidade de organizações não corporativistas adquiriu acesso institucionalizado ao Estado. Como nos sistemas corporativistas, a criação desses "domínios de agência" transforma não somente a estrutura estatal, mas também as práticas sociais. Ao oferecer categorias analíticas para definir os diferentes modos pelos quais "encaixes institucionais" operam na intermediação de interesses, 
os autores adicionam preciosos conceitos à nossa caixa ainda bastante vazia de ferramentas teóricas para enxergar e explicar a complexa relação entre movimentos e instituições. Os organizadores deste livro, junto com os autores dos capítulos, apresentam, assim, mais uma contribuição criativa e inovadora do pensamento político-social brasileiro à literatura internacional sobre a relação entre sociedade e Estado.

Rebecca Abers (UnB) 